\title{
Manual verses automatic inline ventricular function assessment using MRI
}

\author{
Marie Wasielewski ${ }^{*}$, Asad A Usman ${ }^{1}$, Peter J Weale ${ }^{2}$, James Carr ${ }^{1}$ \\ From 2011 SCMR/Euro CMR Joint Scientific Sessions \\ Nice, France. 3-6 February 2011
}

\section{Objective}

To determine the reliability of inline ventricular function (VF) tracking with cardiac MRI compared to a manual technique.

\section{Background}

Computer-based inline VF software can aid in the quantitative analysis of left ventricular (LV) function. Inline VF automatically locates the LV base and apex, detects endo- and epicardial contours in each cardiac slice and phase, and performs a volumetric calculation to determine ejection fraction (EF), end-diastolic volume (EDV), end-systolic volume (ESV). The method presents an opportunity to reduce data processing time and hence reporting time. We compare three methods of postprocessing: automatic, semi-automatic, and manual.

\section{Method}

A stack of 9-12 SA steady state free precession (SSFP) slices from the base of the myocardium to the apex were obtained on a 1.5 Tesla scanner (MAGNETOM Aera Siemens, Germany). Scanning was achieved using developmental cardiac Day Optimizing Throughput (DOT) engine technology. DOT technology uses landmark based guided scan planning to define long and short axis views. The mitral valve annulus is detected on long-axis cine SSFP images which are subsequently used in the automated analysis.

SA SSFP cine images with inline contours were loaded in Argus (Siemens Workstation, Germany). In the semi-automatic group, Argus appointed contours were manually corrected when more than $50 \%$ of the LV was visualized and adjusted to exclude areas of the outflow tract. The source stack of SA cines were also manually

${ }^{1}$ Northwestern University, Chicago, IL, USA

Full list of author information is available at the end of the article segmented and contoured. Results of all three methods were compared for EF, EDV, ESV, and measuring time.

\section{Results}

Complete results are presented in table 1 . We scanned 20 healthy participants $(41.8 \pm 13 \mathrm{yrs})$. The mean automatic, semi-automatic, and manual EF was $53.8 \%, 66.1 \%$, and $66.7 \%$, respectively. The ESV across groups was 70.8 , 49.7 , and $48.6 \mathrm{ml}$, respectively. Both manual and semiautomatic techniques were statistically significantly different than the automatic technique for EF and ESV $(\mathrm{p}<0.05)$. However, the mean EDV across the groups was not statistically significantly different $(\mathrm{p}>0.05)$ 151.3, 144.8, and $143.7 \mathrm{ml}$, respectively. Figures 1, 2, 3

\section{Conclusion}

We found that automated basal slice contours in endsystole can cause significant discrepancy in VF estimation. The decision to include the basal slice is the largest potential source of error in the accuracy of LV assessment. We suggest a semi-automated technique using a

\section{Table 1}

\begin{tabular}{llll}
\hline Demographics & \multicolumn{3}{l}{} \\
\hline $\begin{array}{l}\text { Mean Age (yrs) } \\
\text { Gender }\end{array}$ & $\begin{array}{l}\text { 41.8 }( \pm 13) \\
8 \text { Females \& } 12 \text { Males }\end{array}$ \\
\hline Results & \multicolumn{3}{l}{} \\
\hline Technique & Automatic & Semi-Automatic & Manual \\
\hline EF (\%) & 53.8 & $66.1^{*}$ & $66.7^{*}$ \\
EDV (ml) & 151.3 & 144.8 & 143.7 \\
ESV (ml) & 70.8 & $49.7^{*}$ & $48.6^{*}$ \\
CO (l/min) & 4.9 & $5.78^{*}$ & $5.78^{*}$ \\
SV (ml) & 80.3 & $95.1^{*}$ & $95^{*}$ \\
Mean Measuring & 0 & $3: 55^{*}$ & $5: 55^{*}$ \\
Time (min:sec) & & & \\
\hline
\end{tabular}

*Indicates $p<0.05$ statistical significance of group compared to automatic technique as a standard reference. 


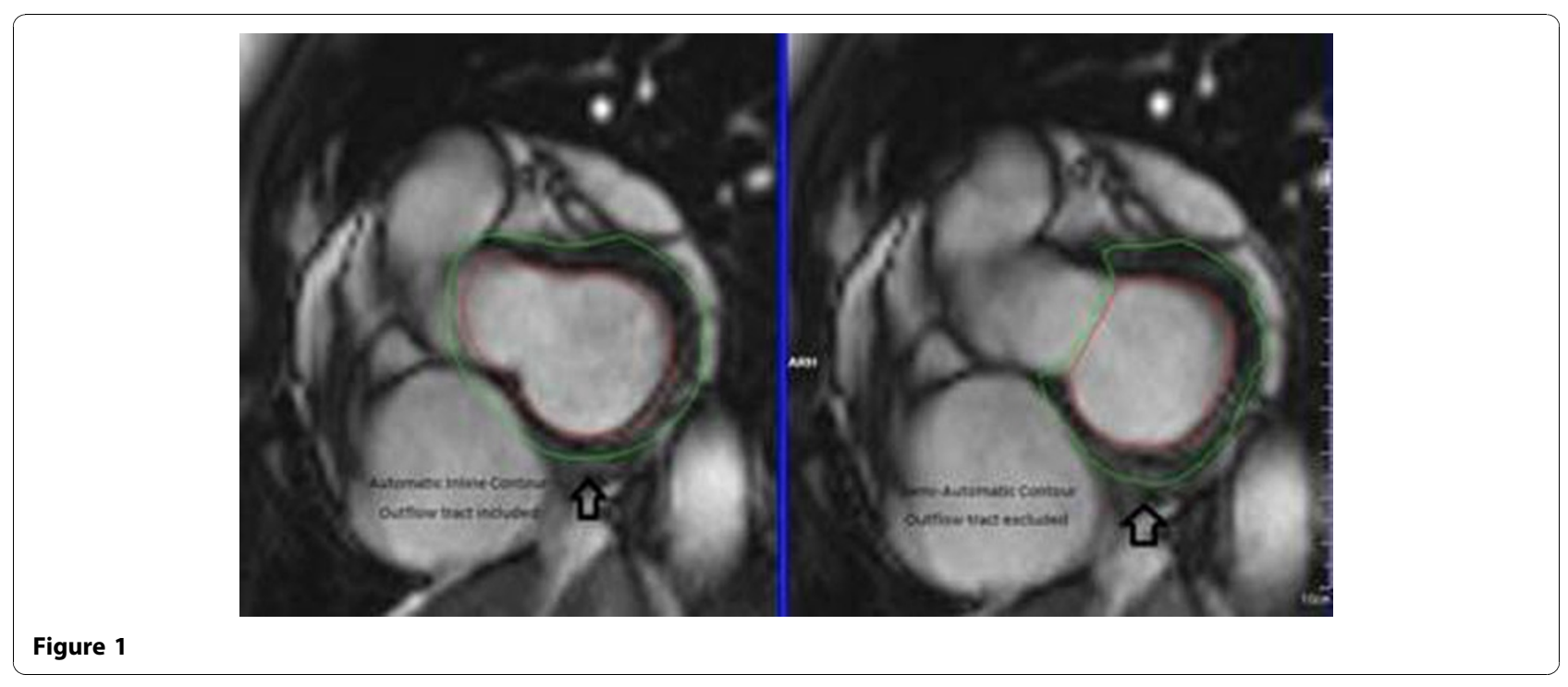

Figure 2
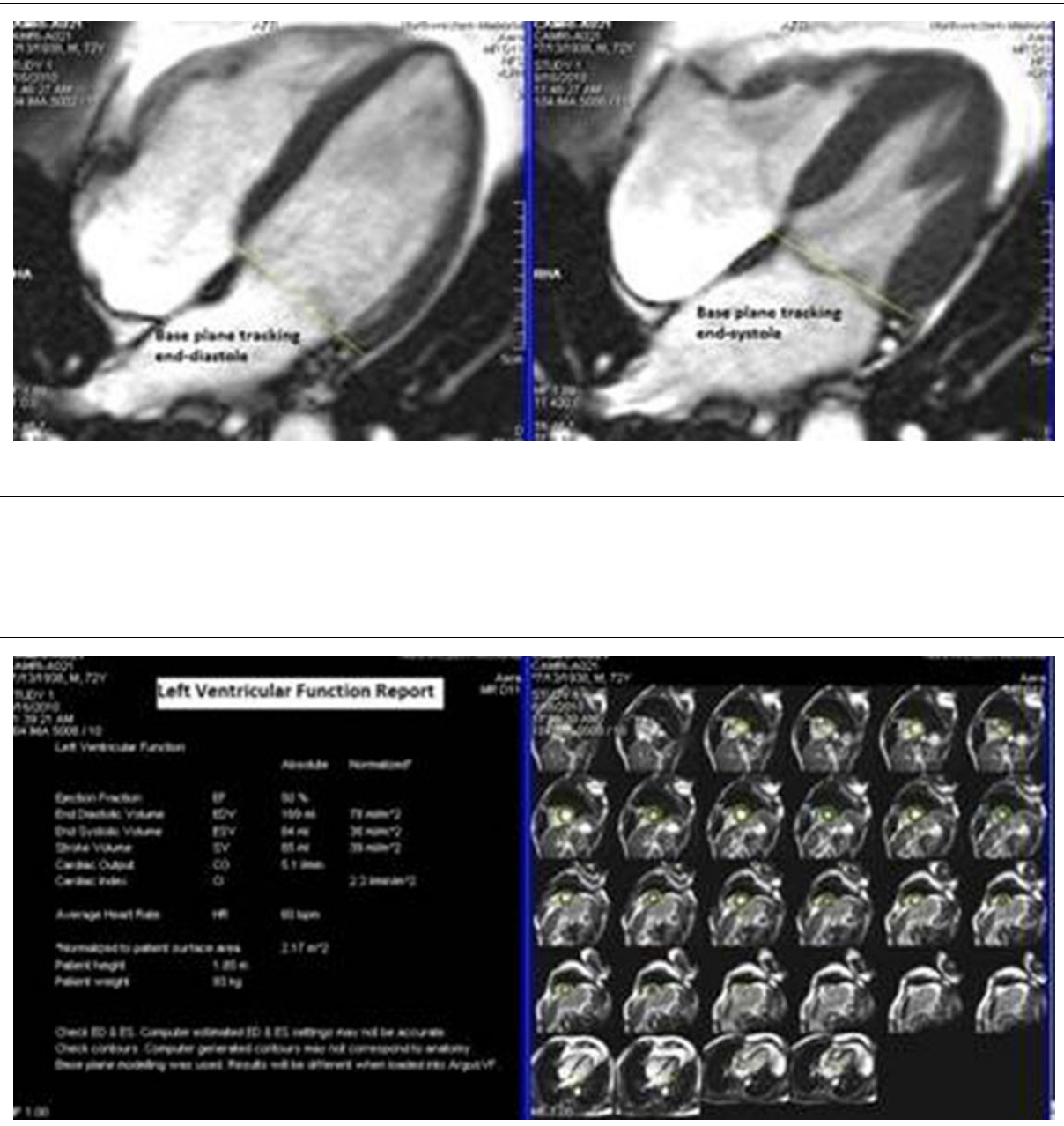

Figure 3 
mix of automated and manual apical and basal correction of contours, to strike a balance between the precision of VF analysis and time when evaluating cardiac function.

\section{Author details}

${ }^{1}$ Northwestern University, Chicago, IL, USA. ${ }^{2}$ Siemens Healthcare, Chicago, IL, USA

Published: 2 February 2011

doi:10.1186/1532-429X-13-S1-P354

Cite this article as: Wasielewski et al: Manual verses automatic inline ventricular function assessment using MRI. Journal of Cardiovascular Magnetic Resonance 2011 13(Suppl 1):P354.

Submit your next manuscript to BioMed Central and take full advantage of:

- Convenient online submission

- Thorough peer review

- No space constraints or color figure charges

- Immediate publication on acceptance

- Inclusion in PubMed, CAS, Scopus and Google Scholar

- Research which is freely available for redistribution

Submit your manuscript at www.biomedcentral.com/submit 